\title{
EL CUERPO Y SU AUSENCIA: ESCENARIO Y CONTENIDO DE LA COMUNICACIÓN
}

\author{
Micaela Bunes Portillo (Coord) \\ Belén Blesa Aledo \\ María Tornel Abellán \\ Ana González Baídez \\ Juan José González Ortíz
}

Universidad Católica de Murcia

Resumen: $\dot{2}$ Nos comunicamos de la misma manera estando físicamente presentes que mediados por la tecnología? ¿ Cómo nos relacionamos con imágenes sobre nosotros y cómo nos afecta su publicación? El cuerpo como escenario y como contenido de la comunicación. Esta investigación aborda estas dos preguntas desde tres vías:

Primero, la elaboración de un contexto teórico que sitúa y enfoca desde el análisis filosófico, sociológico y ético el cuerpo como realidad poliédrica, el agenciamiento cuerpotecnología y una manera alternativa de entender la virtualidad. Segundo: las respuestas de los jóvenes, de edades comprendidas entre 17-24 años, a esas dos preguntas formuladas de un modo abierto y sin ningún tipo de consigna previa. Tercero: el modelo axiológico HallTonna, que es tanto una propuesta teórica basada en las visiones del mundo que se albergan en 125 valores que recogen una visión holística sobre el desarrollo humano y organizativo, como una propuesta interpretativa que permite el análisis de las respuestas de los participantes. El trabajo avanza los resultados obtenidos.

Palabras clave: Presencia física; imagen; tecnología; análisis de contenido.

\section{The body and its absence: setting/scenario and content of communication}

Abstract: Do we communicate in the same way when we are physically present than when we do it through technology? How do we relate to images about ourselves and how does the publication of those same images affect us? The body as a stage and as content of communication. This research addresses these two questions in three ways.

Firstly, the elaboration of a theoretical framework that deals with the body as a polyhedral reality from the philosophical, sociological and ethical analysis, the body-technology connections and an alternative way of understanding virtuality. Secondly, young people's answers, aged 17-24 years, to these two questions formulated in an open way and without any previous slogan. Thirdly, the Hall-Tonna axiological model. This model consists of a theoretical proposal, based on 125 values, that reflects a holistic view of the human and organizational development. Besides, it can be considered an interpretative proposal that allows the analysis of the participants' responses. The article advances some of the results obtained in the research.

Keywords: Physical Presence; Image; Technology; Content Analysis. 


\section{Introducción}

En una investigación previa asumimos la realidad múltiple y polifacética del cuerpo. Haciendo una lectura desde las claves axiológicas del modelo HallTonna (HT en adelante), consideramos que en el desarrollo de la vida hay una experiencia múltiple del cuerpo que puede ser leída en sus diferentes fases (autor et al. 2015). El conjunto de la investigación ha puesto en relación el cuerpo con la tecnología en las comunicaciones de los jóvenes estudiantes de edades comprendidas entre los 17 y los 24 años que han participado en este estudio.

En la presente, analizamos e interpretamos los distintos valores presentes en las interacciones cara a cara y en la experiencia compartida de la imagen del cuerpo.

Al igual que el cuerpo es leído desde una perspectiva abierta, la tecnología no es concebida como instrumento, sin más, sino como un valor del modelo HT cuyo significado requiere ciertas matizaciones.

Al delimitar y contextualizar con la mayor precisión posible el problema planteado, recordamos que no se trata de medir la cantidad de comunicación, sino que tratamos de comprender en qué medida la interacción con la tecnología modifica nuestro ser, nuestra experiencia corporal, nuestras relaciones y maneras de ver el mundo.

Si ya de por sí, el cuerpo es una realidad compleja por cuanto comporta e integra distintos planos y dimensiones (biológica, social, simbólica, axiológica...) que se afectan entre sí poniendo en cuestión sus límites, la relación del cuerpo con la tecnología complica aún más las cosas. A este respecto, nos parece que no es posible abordar legítimamente el modo como nos afectan y afectamos a las tecnologías sin tratar de llevar la lógica de la tecnología hasta el final lo que, sin duda, ha de conducirnos a una revisión de cuáles son o dónde están los límites del cuerpo y de su realidad, cómo afecta esa relación a nuestra libertad, así como a replantear el sentido de lo virtual. Estas exploraciones son las que nos permite la Tecnología concebida como valor.

Empujar la lógica de la tecnología hasta el final implica apelar a la diferencia historia/devenir. Para devenir hay que sustraerse a las condiciones históricas, y es que las posibilidades que brinda la tecnología no se pueden abordar desde un historicismo contextual porque perderían parte de su potencial, al igual que sucede con el arte (Žižek 2006: 32). En palabras de Ihde (ibid, p. 122), la tecnología no se puede reducir a las funciones para las que ha sido creada porque las posibilidades que mueve las trasciende y porque la propia divergencia que caracteriza la vida, permite que emerjan usos distintos a los iniciales y cambios a nivel humano completamente imprevistos.

Abordar de esta manera la tecnología nos enfrenta directamente a una revisión de lo que entendemos por virtualidad. La virtualidad que permite la tecnología concebida desde la perspectiva del valor, no necesariamente se 
garantiza con el uso de la tecnología como instrumento, ni se entiende exclusivamente como reproducción o representación de la realidad. Lo virtual supone la creación de nuevas posibilidades de experiencia, pensamiento, sensibilidad; es una transición del acto a la potencia y no al revés (Pardo 2011: 93). Las implicaciones de este movimiento dan cuenta de la interacción incesante actualidad-virtualidad que compromete la realidad, todo ello relacionado con la experiencia del tiempo que rebasa el actualismo, la linealidad e introduce el devenir. Sí, la cuestión del tiempo es un elemento clave al analizar la tecnología porque la lógica del cambio que supone la tecnología hace históricamente viable una forma de vida experimentada más como devenir que como ser. (Bärd y Sãderqvist 2002).

Una cuestión de interés es cómo se combinan cuerpo y máquina teniendo en cuenta el hecho de que las máquinas (relacionadas con la comunicación) están en la transición de ser aparatos externos para convertirse en parte de nuestra auto-experiencia (Žižek, ibid, p. 35).

Un posible problema que plantea la interacción mediada por la tecnología en rélación al cuerpo es el de su deslocalización, pero este problema compete al cuerpo entendido como entidad puramente física, y no como acumulación intensiva de singularidades y velocidades en las que se ve implicado el cuerpo en sus relaciones, donde la experiencia trasciende al propio cuerpo entendido como ese centro de la experiencia marcado por la sensorialidad y las certidumbres perceptuales. Se trata del espacio relacional del que hablaba el biólogo Humberto Maturana (1996), que se da en el conversar y que presupone el lenguaje. Un lenguaje que configura y enuncia la experiencia de otra manera, sin hacerla pasar por los registros dominantes en la ciencia "porque nada en el operar del sistema nervioso representa lo que pasa en las relaciones e interacciones del individuo en su medio" (Maturana, ibid, p. 189). No hay paralelismo entre el funcionamiento del sistema nervioso y lo que el individuo realiza en su medio y esto sucede porque también existimos en el lenguaje y la tecnología permite mantener redes de conversaciones con límites y posibilidades, como sucede en el espacio ocupado por el cuerpo físico, porque el cuerpo también está en el lenguaje y se ve afectado por él. Estas formas de estar en el vivir, estas redes de conversaciones que constituyen innumerables tramas culturales, "se entrelazan con lo fisiológico en una continua modulación recíproca y nuestra corporalidad se configura en y con su participación" (ibid, p. 195).

El espacio relacional tiene una historia muy anterior a la de sus protagonistas. La deslocalización del cuerpo no supone necesariamente una pérdida de referencias, sino el abandono de los intentos de objetivación visual que proyecta la mirada del observador, lo que apunta hacia nuevas posibilidades en la consideración de lo virtual. Cuando Ihde, desde el marco fenomenológico, sitúa la experiencia total en la percepción como compendio de la experiencia sensorial, deja al margen la posibilidad de experiencia que trae consigo el lenguaje no entendido como sistema de signos sin más, sino en su capacidad de crear realidad y sentido, y en cómo el cuerpo no queda al margen de esta experiencia. Así, no deja de haber 
virtualidad en la experiencia que sucede al emocionarnos con un poema o con los personajes de una novela. La lectura múltiple del cuerpo conduce a la posibilidad de localización a otro nivel de experiencia. Entonces, la cuestión de la virtualidad tal vez no haya que plantearla como una realidad paralela, mirada bajo la sospecha de ser un simulacro, un remedo o un sucedáneo.

A partir de aquí se hace pertinente introducir una breve reflexión acerca de la imagen, también en clave de valor contemplado por el modelo HT.

La hiperbolización social y culfural de la imagen corporal ha traído consigo una reducción del cuerpo a su apariencia, ensalzando su estética y marginando otras posibilidades. Lo que la ciencia ha sido capaz de representar visualmente se ha constituido en evidencia. El proceso de trasferencia ha ocasionado que la imagen del cuerpo haya tomado mayor protagonismo y mayor realidad que el propio cuerpo. La imagen permite su observación prolongada, aislando las variables de un contexto restringido, detenido y menos perturbador. La atención focalizada que se concentra sobre los aspectos visuales constituye una de las síntesis primarias de la percepción total (ldhe, ibid, p. 59).

Vivir en los medios supone construir otros modos de experiencia que apuntan a la ruptura de la separación dentro-fuera, público-privado, encarnadodesencarnado, sin perder de vista las relaciones de poder que forman parte del entramado mediático.

Puesto que ahora el mensaje es el usuario, su imagen en este caso, el atractivo que rodee a la imagen puede ser una garantía de éxito, además de acarrear juicios estéticos y también morales. La imagen propia es un valor complejo que media en la relación con uno mismo y con otros. Si no queda demasiado sofocada por la búsqueda del éxito, lo que es frecuente entre los más jóvenes, la imagen es una vía de Expresividad/Libertad y de Autoafirmación, valores del modelo HT, que apuntan tanto hacia el valor meta Desarrollo personal/profesional, como a otros valores como la Intimidad - la Presencia. Pero, para muchos jóvenes, instalados en protectores entornos familiares, suele ser difícil el acceso a experiencias de la imagen asociadas a esos otros valores más complejos.

A este respecto, el resultado del Proyecto Scopio (Centro Reina Sofía sobre Adolescencia y Juventud 2016), muestra el importante retraso, en todas las comunidades autónomas, de sus índices globales de desarrollo juvenil respecto de la media europea general. Los datos de empleo, educación y emancipación son los que dan cuenta del mismo. En materia tecnológica, los jóvenes españoles están bien posicionados frente a los europeos aun existiendo diferencias entre comunidades autónomas.

El Instituto de la Juventud publicó una revisión de los estudios realizados en España sobre juventud y nuevas tecnologías en las últimas tres décadas (Puente et al. 2015). Sus autores concluyen señalando la necesidad de utilizar enfoques que permitan ir más allá de la descripción de las abundantes, y tal vez peligrosas, relaciones que los jóvenes mantienen con las tecnologías. Los 
afectos, sentimientos y deseos que están presentes en estas relaciones, operan con una lógica que necesita ser abordada con la metodología adecuada (Lasén y Casado 2014). Creemos que el modelo HT (Hall 1986; 1995; 2000) seleccionado para esta investigación, lo permite.

El objetivo general de esta investigación ha sido realizar una aproximación a la experiencia del cuerpo como lugar y contenido fundamental de la comunicación de los jóvenes utilizando las categorías axiológicas del modelo HT para analizar, primeramente, e interpretar después, la experiencia referida. Para ello se ha trabajado sobre-las respuestas a dos preguntas planteadas a los estudiantes de enseñanzas postobligatorias y universitarias participantes en esta investigación.

\section{Metodología}

Se trata de una investigación cualitativa basada en el modelo Hall-Tonna, en la que se han empleado distintas técnicas de análisis (de contenido y análisis comparados) para el tratamiento e interpretación de las respuestas dadas por jóvenes estudiantes de enseñanzas postobligatorias y universitarias, a las preguntas planteadas por los investigadores.

El modelo Hall-Tonna es una propuesta metodológica comprehensiva que recoge distintas visiones del mundo que se proponen para explicar el desarrollo humano y de las organizaciones, contenidas en 125 valores, categorías axiológicas que permiten dialogar de forma sincrética con las teorías filosóficas, sociológicas y psicológicas que se han utilizado para componer el marco teórico de esta investigación. El modelo tiene su origen en la Universidad de Santa Clara (California) y fue su creador el Dr. Brian P. Hall, profesor de Consejo Psicológico de aquella universidad conjuntamente con el profesor Benjamin Tonna de la Universidad de La Valletta (Malta), doctor en Sociología y director del centro de documentación internacional SEDOS. A partir de una primera propuesta de valores que los autores fueron puliendo, se dio lugar a la creación de unos instrumentos para su reconocimiento y análisis, que permiten la identificación de valores personales y grupales a través de un cuestionario único. Un programa informático procesa las respuestas (individual o conjuntamente) y genera un voluminoso informe como propuesta de trabajo. En documentos textuales, ese mismo reconocimiento se realiza a través del programa de análisis de contenido utilizado en esta investigación. El análisis de valores en documentos se basa en el supuesto de que los documentos escritos comunican los valores a través de las palabras usadas para crearlos. Los 125 valores del modelo Hall-Tonna constituyen las categorías interpretativas del programa.

Los valores son el núcleo central que permite comprender el dinamismo de las personas. Los valores engloban ideales, intereses, motivaciones y necesidades que rigen la conducta y están en la base de las decisiones individuales y organizativas. 
El desarrollo de los valores se estructura en cuatro fases (Seguridad, Pertenencia, Iniciativa e Interdependencia), que permiten explicar cómo, a lo largo de la vida, las prioridades de valor cambian, y cómo se produce este desarrollo. El tránsito por las fases de desarrollo humano está asociado a distintas visiones del mundo que reflejan diferentes maneras de entender y situarse en la realidad. Cada una de las fases incluye un conjunto de valores del ámbito individual (etapas impares) y otro conjunto de valores del ámbito institucional (etapas pares). El crecimiento requiere integrar valores personales y organizacionales en cada una de las fases del desarrollo. Por tanto, un total de ocho etapas, dos en cada una de las cuatro fases, completan el recorrido de los valores. En cada fase, algunos valores son metas y otros valores son medios que muestran el camino para alcanzar las primeras. Para que las personas actúen en su vida personal e institucional movidas por valores de orden superior, es preciso realizar determinados itinerarios o recorridos en los que necesariamente deben estar presentes valores de etapas previas.

En definitiva, el desarrollo de valores puede considerarse como un recorrido o trayectoria que permite avanzar hacia fases más integradas de desarrollo. Los valores básicos son el apoyo necesario para lograr una mayor coherencia entre la conducta y los referentes o ideales.

En esta segunda fase de la investigación han participado 362 estudiantes de enseñanzas postobligatorias no universitarias (Bachillerato y Ciclo Formativo superior) y universitarias (Grado y Máster) de edades comprendidas entre los 17 y los 24 años, encuestados en centros públicos de secundaria y en universidades públicas de Murcia y de la Comunidad Valenciana.

El muestreo ha sido intencional y el criterio de selección de los sujetos ha sido su edad. Según los datos ofrecidos por el Instituto Nacional de Estadística (1 4 de diciembre de 2016), son los jóvenes de edades comprendidas entre los 16 y los 24 años, los que más se conectan a Internet, con muy pequeñas variaciones entre chicos y chicas: un $98,6 \%$ de varones, frente al $98,2 \%$ de mujeres. Al aumentar los intervalos de edad, descienden los porcentajes de uso en unos y en otras. Las edades coinciden con el acceso y permanencia en las enseñanzas postobligatorias que se cursan en centros de secundaria y en universidades. Allí se ha buscado a los sujetos que han participado en esta investigación.

Los jóvenes estudiantes de Bachillerato y universitarios disponen de mayores espacios de libertad que los adolescentes de ESO, al disminuir progresivamente el control parental e institucional sobre sus movimientos salen fuera del domicilio familiar y del espacio institucional del instituto o de la universidad para quedar con sus colegas- y sobre sus tiempos de conexión, situaciones de relevancia en este estudio, por razones que se desprenden de los enunciados de las preguntas planteadas a los estudiantes que se presentan a continuación. 
Después de testar algunas formulaciones iniciales y tras varias reuniones del equipo investigador, éstas han sido las preguntas abiertas planteadas a los estudiantes:

1. $\quad \dot{z}^{T e}$ comportas de diferente manera cuando te comunicas con tus amigos cara a cara o cuando lo haces a través de redes, whatsapp, etc.?

2. Cuándo te comunicas por redes ite lo piensas antes de subir las imágenes que compartes de ti mismo/a? ¿Crees que tus amigos/as se 10 piensan?

Los mismos jóvenes son los que han establecido las diferencias y los matices de sus conversaciones, así como sus opciones y preferencias personales. Las preguntas, formuladas por escrito, se han planteado sin límites de espacio ni de tiempo, sin consignas, sin interpretaciones ni instrucciones, para garantizar la libre autodeterminación expresiva de los sujetos que han respondido anónimamente a ellas.

Se ha analizado el contenido de las respuestas con una herramienta de análisis documental que utiliza las categorías axiológicas del modelo HT, herramienta de acceso online, gestionado por la Universidad de Deusto. Se ha dispuesto de los permisos necesarios para el acceso y uso del programa.

El programa de análisis Hall-Tonna Documents (Valuestech 2002) escanea los términos literales de los valores HT sobre el texto. Este primer reconocimiento puede ser confirmado o no por el equipo que realiza el análisis. Los miembros del equipo investigador trabajaron previamente sus valores, respondiendo al cuestionario HTINVE Hall-Tonna Inventory (Hall, Harari, Ledig and Tondow 1986) y todos se orientan con precisión en el mapa de valores del modelo HT.

La segunda técnica de análisis empleada ha sido la comparación de los perfiles de valores resultado de procesar las respuestas agrupadas de los y las estudiantes a cada una de las preguntas formuladas. La opción de agrupar las respuestas permite dar mayor consistencia a la investigación ya que el análisis de textos demasiado breves no podría ser interpretado correctamente.

En total han sido entrevistados un total de 362 estudiantes, 171 de enseñanza secundaria postobligatoria y 191 universitaria. Concretamente, han participado estudiantes de-Bachillerato, Ciclo Formativo Superior de Comercio Internacional (procedentes de dos centros públicos de secundaria de la Región de Murcia), Grado en Educación Infantil, Grado en Lengua y Literatura, Grado en Biotecnología y Máster en Formación de Profesorado de Secundaria (procedentes de universidades públicas de la Región de Murcia y la Comunidad Valenciana).

Se prescindió de las respuestas de los estudiantes mayores de 24 años, depurándose hasta las 304 al seleccionar solo las de contenido analizable. Se despreciaron los monosílabos como respuesta (sí-no) o la réplica exacta de 
la pregunta formulada precedida del monosílabo, pero solo en el caso de coincidir en las dos respuestas.

Se transcribieron con un procesador todas las respuestas manuales, componiendo dos textos planos con las respuestas a cada una de las preguntas. Cada respuesta se corresponde con un párrafo que enumera el programa de análisis, lo que permite asociar los datos conocidos del estudiante encuestado: sexo, edad y estudios que cursa.

Como resultado de analizar el contenido de los dos textos, se han obtenido dos perfiles con los valores identificados en cada uno de ellos. El equipo de investigación discute tas asociaciones de valores que realiza el programa, añadiendo nuevos valores de contexto después de confirmar o rechazar el análisis literal (en parte o en su totalidad). Completado este trabajo, se obtienen de nuevo los perfiles de valores definitivos para proceder a su comparación.

\section{Resultados}

En las tablas siguientes (I y II), se presentan los perfiles de valores (resaltados en negrita), obtenidos como resultado de analizar las respuestas a cada una de las preguntas planteadas.

1) ॥ ॥ TABLA I (poff)

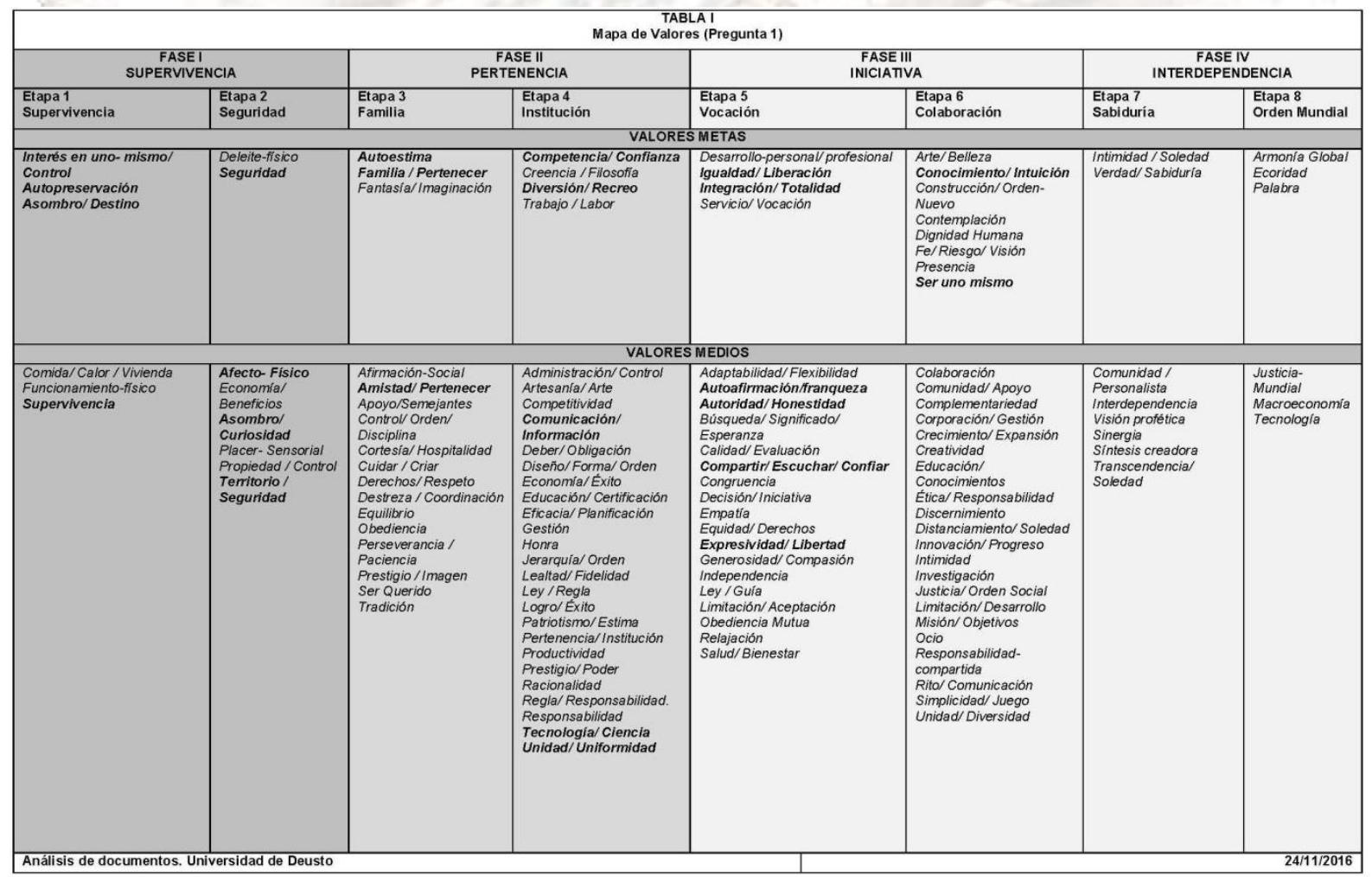


" » " " TABLA || (pdf)

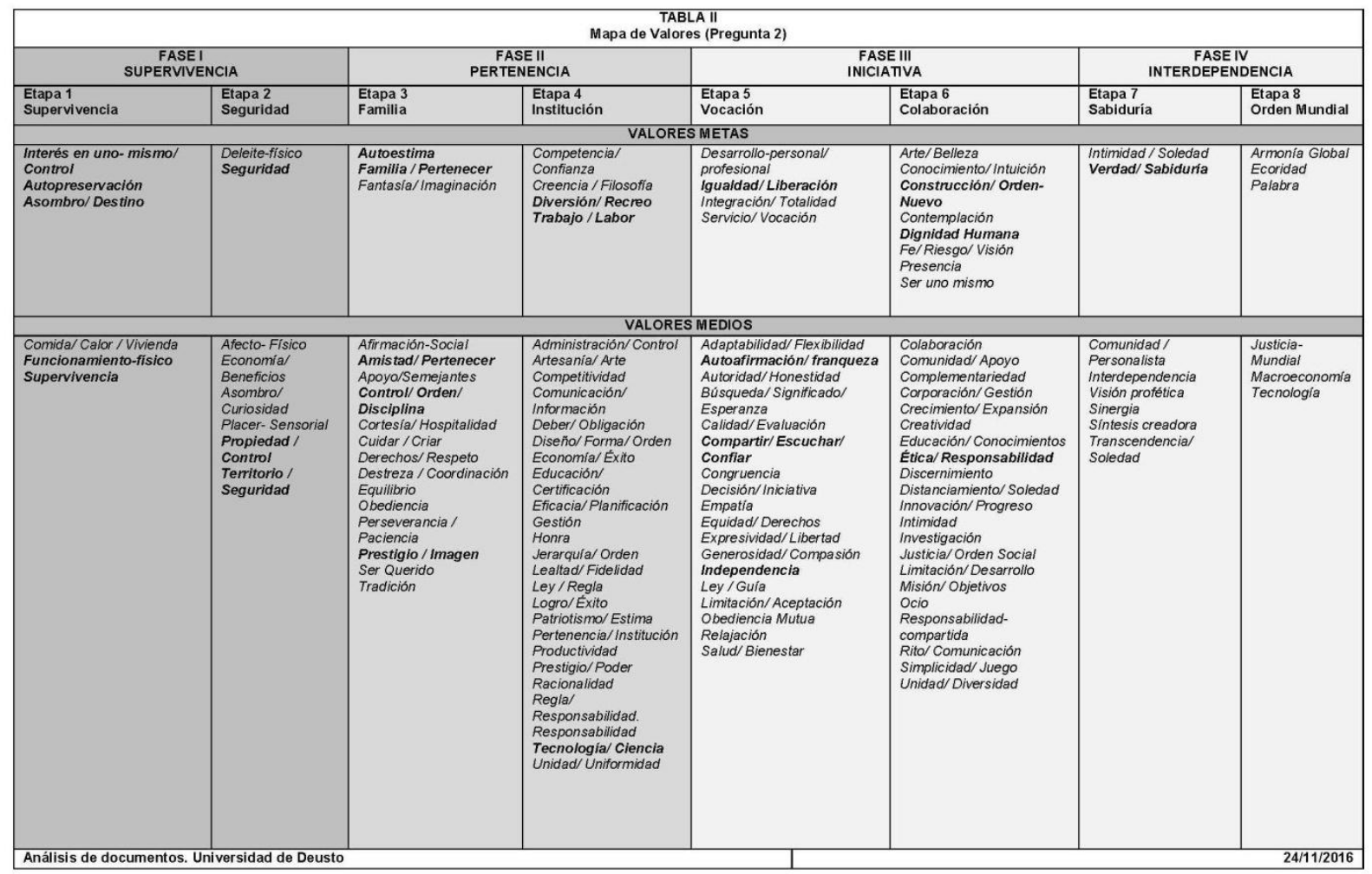

La similitud de estos dos perfiles es el primer aspecto a reseñar. La misma muestra de estudiantes ha respondido a estas dos preguntas y sus respuestas son consecuentes. Pero los perfiles que se comparan en esta fase del trabajo también muestran diferencias. El primero (Tabla I) se encuentra algo más 'adelantado' en el mapa de valores que el segundo (Tabla II), aunque están en el mismo Ciclo de desarrollo (sombreado central) compuesto por las etapas 3-4 (Familia-Institución) que conforman la Fase II de Pertenencia. Los valores identificados en las respuestas a la primera pregunta desvelan un esfuerzo mayor por controlar la propia vida y tener éxito, mientras que los valores identificados en las respuestas a la segunda pregunta, apuntan en sentido contrario: la propia supervivencia depende de otros, sobre todo de la familia. La tendencia regresiva de estos valores puede indicar que la imagen del cuerpo proporciona mayores dudas, inseguridades y amenazas que su presencia física.

Los valores identificados en los dos textos compuestos por las respuestas de los estudiantes a la primera y segunda preguntas, pueden analizarse desde dos perspectivas que proporcionan visiones complementarias. La primera es la que acabamos de considerar. Se trata de contemplar los valores identificados a través de las etapas y fases del mapa de valores: una visión que muestra el dinamismo interno encerrado en los dos grupos de valores que componen cada uno de los perfiles. La otra perspectiva muestra esos mismos valores ordenados según sus frecuencias de elección. Esta visión de 
los valores como prioridades es complementaria a la anterior y pone de manifiesto que los mismos valores pueden movilizar distintas conductas, dependiendo de cuáles sean las prioridades con las que hayan sido elegidos.

A continuación, se presentan los valores ordenados según prioridades. En la tabla III, los correspondientes a las respuestas a la primera pregunta y en la tabla IV, Ios correspondientes a la segunda, antes de realizar una lectura conjunta de la información contenida en las cuatro tablas.

") $\| »$ TABLA III (pdf)

\begin{tabular}{|c|c|c|c|c|c|}
\hline \multicolumn{6}{|c|}{$\begin{array}{c}\text { TABLA III } \\
\text { Valores seleccionados (Pregunta 1) }\end{array}$} \\
\hline Valores Meta & Etapa & $\begin{array}{r}\text { Veces } \\
\text { elegido }\end{array}$ & Valores medio & Etapa & $\begin{array}{l}\text { Veces } \\
\text { elegido }\end{array}$ \\
\hline Seguridad & 2 & 75 & Tecnología/Ciencia & 4 & 243 \\
\hline Autopreservación & 1 & 23 & Comunicación/Información & 4 & 171 \\
\hline Interés en uno mismo/control & 1 & 15 & Amistad/Pertenecer & 3 & 80 \\
\hline Igualdad/Liberación & 5 & 15 & Unidad/Uniformidad & 4 & 45 \\
\hline Competencia/Confianza & 4 & 14 & Compartir/Escuchar/Confiar & 5 & 45 \\
\hline Familia/Pertenecer & 3 & 9 & Expresividad/Libertad & 5 & 38 \\
\hline Ser uno mismo & 6 & 9 & Autoafirmación/Franqueza & 5 & 28 \\
\hline Autoestima & 3 & 7 & Control/Orden/Disciplina & 3 & 25 \\
\hline Diversión/recreo & 4 & 5 & Eficacia/Planificación & 4 & 22 \\
\hline Asombro/Destino & 1 & 3 & Racionalidad & 4 & 12 \\
\hline Integración/totalidad & 5 & 2 & Supervivencia & 1 & 11 \\
\hline Conocimiento/intuición & 6 & 2 & Administración/Control & 4 & 10 \\
\hline Dignidad humana & 6 & 2 & Autoridad/Honestidad & 5 & 9 \\
\hline Trabajo/Labor & 4 & 1 & Ley/Regla & 4 & 8 \\
\hline Presencia & 6 & 1 & Adaptabilidad/Flexibilidad & 5 & 8 \\
\hline Verdad/Sabiduría & 7 & 1 & Congruencia & 5 & 8 \\
\hline & & & Limitación/Aceptación & 5 & 8 \\
\hline & & & Territorio/Seguridad & 2 & 7 \\
\hline & & & Independencia & 5 & 7 \\
\hline & & & Deber/Obligación & 4 & 5 \\
\hline & & & Afecto fisico & 2 & 4 \\
\hline & & & Asombro/Curiosidad & 2 & 4 \\
\hline & & & Afirmación social & 3 & 4 \\
\hline & & & Equilibrio & 3 & 4 \\
\hline & & & Prestigio/Imagen & 3 & 4 \\
\hline & & & Cortesía/Hospitalidad & 3 & 3 \\
\hline & & & Gestión & 4 & 3 \\
\hline & & & Empatía & 5 & 3 \\
\hline & & & Intimidad & 6 & 3 \\
\hline & & & Propiedad/Control & 2 & 2 \\
\hline & & & Derechos/Respeto & 3 & 2 \\
\hline & & & Lealtad/Fidelidad & 4 & 2 \\
\hline & & & Tecnología & 8 & 2 \\
\hline
\end{tabular}




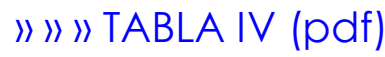

\begin{tabular}{|c|c|c|c|c|c|}
\hline \multicolumn{6}{|c|}{$\begin{array}{c}\text { TABLA IV } \\
\text { Valores seleccionados (Pregunta 2) }\end{array}$} \\
\hline Valores Meta & Etapa & $\begin{array}{r}\text { Veces } \\
\text { elegido }\end{array}$ & Valores medio & Etapa & $\begin{array}{r}\text { Veces } \\
\text { elegido }\end{array}$ \\
\hline Autopreservación & 1 & 47 & Amistad/Pertenecer & 3 & 198 \\
\hline Interés en uno mismo/control & 1 & 45 & Tecnología/Ciencia & 4 & 115 \\
\hline Autoestima & 3 & 37 & Prestigio//magen & 3 & 69 \\
\hline Seguridad & $\overline{2}$ & 21 & Control/Orden/Disciplina & 3 & 43 \\
\hline Familia/Pertenecer & 3 & 11 & Propiedad/Control & 2 & 35 \\
\hline Trabajo/Labor & 4 & 7 & Comunicación//nformación & 4 & 26 \\
\hline Asombro/Destino & 1 & 5 & Territorio/Seguridad & 2 & 25 \\
\hline Diversión/recreo & 4 & 3 & Afirmación social & 3 & 22 \\
\hline Deleite físico & 2 & 2 & Compartir/Escuchar/Confiar & 5 & 17 \\
\hline Competencia/Confianza & 4 & 2 & Derechos/Respeto & 3 & 14 \\
\hline Igualdad/Liberación & 5 & 1 & Independencia & 5 & 14 \\
\hline Construcción/Orden Nuevo & 6 & 1 & Supervivencia & 1 & 13 \\
\hline Dignidad humana & 6 & 1 & Racionalidad & 4 & 11 \\
\hline Verdad/Sabiduría & 7 & 1 & Unidad/Uniformidad & 4 & 11 \\
\hline & & & Autoafirmación/Franqueza & 5 & 9 \\
\hline & & & Ética/Responsabilidad & 6 & 9 \\
\hline & & & Deber/Obligación & 4 & 8 \\
\hline & & & Regla/Responsabilidad & 4 & 7 \\
\hline & & & Responsabilidad & 4 & 6 \\
\hline & & & Responsabilidad Compartida & 6 & 6 \\
\hline & & & Expresividad/Libertad & 5 & 4 \\
\hline & & & Limitación/Aceptación & 5 & 3 \\
\hline & & & Apoyo/Semejentes & 3 & 2 \\
\hline & & & Administración/Control & 4 & 2 \\
\hline & & & Artesanía/Arte/Oficio & 4 & 2 \\
\hline & & & Ley/Regla & 4 & 2 \\
\hline & & & Logro/éxito & 4 & 2 \\
\hline & & & Decisión/iniciativa & 5 & 2 \\
\hline
\end{tabular}

Los 125 valores del modelo se agrupan en los perfiles en tres áreas: valores de base, centrales y futuros, que están sombreadas en distintas saturaciones, comenzando por los valores de base, a la izquierda de las tablas I y II. Las áreas de valores comparadas en la primera y segunda pregunta, arrojan los siguientes resultados:

En las áreas de base se encuentran los mismos valores metas con distintas prioridades. En las respuestas a la primera pregunta, el valor Seguridad (etapa 2) es la meta prioritaria y en la segunda, lo es la Autopreservación (etapa 1). Conviene destacar que en la base se sitúan los yalores prioritarios de los dos mapas de valores. Este dato indica que la seguridad se ve con frecuencia amenazada por la pérdida o el daño y que se busca protección mediante el control, el escape o el ocultamiento. Estas conductas de temor ralentizan el desarrollo hacia valores más integrados, también presentes en los perfiles analizados, aunque con distinta prioridad. En cuanto a los medios, en las respuestas a la primera pregunta, no están los valores medios del área entre las prioridades más altas, si en la segunda, en la que se encuentran los valores: Propiedad/control y Territorio/seguridad, que son valores medios de la etapa 2.

En el área central (etapas 3 y 4) los cuatro valores metas prioritarias en ambos perfiles difieren en una sola elección: Competencia/confianza (etapa 
4), en las primeras respuestas y Trabajo/labor, en las segundas (etapa 4). Los valores Autoestima (etapa 3) y Familia/pertenecer (etapa 3) tienen más elecciones en las respuestas a la segunda pregunta que en las de la primera, sobre todo el primero de ellos. El valor Autoestima está directamente relacionado con el valor de la imagen.

Los medios difieren más. Solo uno de los tres medios de la etapa 3 coincide en las respuestas a las dos preguntas: Amistad/pertenecer, siendo en ambos perfiles de alta prioridad (de máxima en las respuestas a la segunda pregunta). De la cuarta etapa coincide también uno de los tres valores medio elegidos. En esta ocasión es el valor Tecnología/ciencia, de alta prioridad en las dos series de respuestas, máxima prioridad en la primera. Los otros medios son: Comunicación/información y Unidad/Uniformidad, en las respuestas a la primera pregunta y Control/Orden/disciplina y Prestigio/imagen, en la segunda.

Del área de futuro difieren las metas en los dos mapas, en la misma proporción que en las etapas del área central, en este caso, en las cuatro etapas finales. Coincide solo uno de los cuatro valores metas seleccionadas en los dos mapas de valores: Igualdad/liberación (etapa 5), aunque es de prioridad más alta en la primera. Las metas de las respuestas a la segunda pregunta tienen mayor alcance: avanzan hacia las etapas finales, aunque con escasa prioridad.

En cuanto a los valores medios, todos los de las respuestas a la primera pregunta están en la etapa 5. Los medios prioritarios son: Compartir/Escuchar/Confiar, en los dos perfiles; Expresividad/Libertad, en el primero e Independencia, en el segundo.

En resumen, la Seguridad (etapa 2) es el valor meta prioritario de la primera pregunta y Autopreservación (etapa 1) de la segunda, casi con la misma frecuencia que Interés en uno/control (etapa 1). Es más regresivo el perfil de la segunda pregunta y sus valores traslucen riesgos y mayores amenazas.

Los medios reflejan la misma lógica de las metas, tal vez reforzada. En las respuestas a la primera pregunta son las habilidades tecnológicas (Tecnología/Ciencia) las que permiten a los jóvenes sentirse competentes, confirmando su Seguridad y manteniéndolos a salvo de algunas amenazas. En la segunda pregunta, lo que permite sobrevivir es la pertenencia (Amistad/Pertenecer). En la primera se da un pequeño paso al frente en el sentido de buscar afianzamiento y autonomía, a partir del desarrollo de habilidades que aumentan la competencia y confianza en uno mismo.

\section{Interpretación y discusión de resultados}

Comenzamos con las respuestas a la primera pregunta: La comunicación cara a cara implica, para los y las estudiantes entrevistadas, mayor riesgo. Más allá de que la presencia corporal desvele rasgos propios al interlocutor que no se conocen ni se controlan, su presencia, nunca es poseída del todo ya que no se agota y eso genera incertidumbre y temor. El cuerpo nunca es 
neutro y la disociación experimentada (mi cuerpo/yo) es foco generador de dudas e inestabilidad y activador de la búsqueda de nuevas seguridades y garantías. De ahí la prioridad concedida al valor Seguridad, meta de la etapa 2.

El valor meta Autopreservación, de la etapa anterior, manifiesta la tendencia regresiva del primer perfil, aunque de forma menos acusada que en el segundo. Informa sobre la percepción de amenazas a una seguridad que está débilmente asentada en muchos estudiantes. Estas amenazas pueden hacer referencia a experiencias internas y también a coyunturas externas que son compartidas por la mayoría y que pronostican un incierto futuro. El valor informa sobre la búsqueda de los medios que permiten escapar, ponerse a salvo de los daños, evitar nuevas pérdidas tanto materiales como afectivas, reales o percibidas.

En líneas generales, los estudiantes manejan mejor la tecnología que su propia persona. Hay una confianza en el uso de los medios (Tecnología/Ciencia, valor medio de la etapa 4) que se asocia al valor meta, de la misma etapa, Autocompetencia/confianza. Este valor puede falsear la confianza real en uno mismo, a la vista de los perfiles de valores completos que se han obtenido. Queda trabajo pendiente con la estima propia ya que se trata de un camino que se va trazando con dificultades, aunque reforzado por una personalidad mediática que se construye en la red.

Sin embargo, esto no evita encontrar algunas respuestas en las que el propio medio también es puesto en duda por su rigidez y por las ambigüedades a las que da lugar. Sus limitaciones preocupan, pues pueden desvirtuar el mensaje y lo peor, a ellos mismos. Esta es la respuesta de un estudiante de Bachillerato, de 17 años:

"No, no me gusta hablar con mis amigos por redes sociales ni mucho menos conocer a gente porque, además de generar confusiones debido al tono utilizado, nos perdemos muchas sensaciones al utilizar redes, una mirada sincera, una risa nerviosa, un abrazo..." (1/73).

Los jóvenes estudiantes se resisten a ser desfigurados. Al respecto, y aunque adopten posiciones extremas en sus respuestas a las preguntas formuladas, se activa un mecanismo parecido de control. Más para los tecnófilos que para los tecnófobos el valor Interés personal/Control, meta de la etapa 1, suele adoptar la estrategia de controlar cuidadosamente la información que se comparte. Así lo expresa una estudiante del Grado en Educación Infantil, de 22 años: "Sí, cuando me comunico por WhatsApp, Facebook, etc., mido mucho más mis palabras, es decir, no escribo lo primero que se me ocurre pues puede llevar a confusiones y malentendidos (...)" (1/192).

La vergüenza es una emoción que abunda en las respuestas y da precisa cuenta del temor frente a la vulnerabilidad del cuerpo. El medio tecnológico puede ser estrategia de supervivencia pues lo oculta, y ese ocultamiento lo hace fuerte, aunque sólo en apariencia. Cuando la red es un lugar seguro por el miedo al 'cara a cara', las respuestas que intentan justificar un uso eficaz de la expresividad y un buen manejo de la libertad personal, resultan 
valores falseados pues no hay ninguna conquista personal previa que impulse a la libre expresión de uno mismo (valor medio Expresividad/libertad, de la etapa 5). Se trata en realidad de su salvaguarda tecnológica. Esta es la expresiva declaración de una joven estudiante del Máster de Formación de Profesorado: "Sí, por WhatsApp y redes sociales me parece más fácil expresar mis pensamientos (...), porque estos medios parece que actúan como barrera y facilitan nuestra expresión." (1/298).

En un abundante número de respuestas, los y las estudiantes hablan de comportarse siempre igual, con independencia del medio, en la confianza de sentirse en un contexto seguro al estar entre amigos. Esta confianza permite una experiencia básica de la igualdad que remite al valor meta Igualdad/liberación, de la etapa 5. El sentimiento de igualdad (estar entre iguales sean estos colegas, compañeros o amigos), libera la acción. Esto es lo que refiere un estudiante de 23 años de edad, del Ciclo Formativo en Comercio Internacional: "(...) me comporto siempre igual, aunque los temas varíen, ya que con mis amigos puedo ser totalmente yo" (1/154). Se trata de una primera experiencia de la igualdad que es muy importante. Se asocia al valor Unidad/uniformidad, cuando se reconocen al usar siempre el mismo formato: "de la misma forma -afirma un estudiante de Bachillerato de 17 años-, tanto cuando me comunico a través de redes sociales como cuando trato con mis amigos en persona" (1/7), o al valor Control/Orden/disciplina, valor medio de la etapa 3, cuando se hace referencia explícita al deber, a la decencia o a la compostura, como sucede en la respuesta de una joven de 23 años, estudiante de Grado en Educación Infantil: "Con ciertas personas sí que no hablo igual por Whatsapp ya que intentas mantener cierta compostura" (1/197), más alejada de la experiencia liberadora descrita anteriormente.

Es interesante la consideración que realizan algunos estudiantes quienes, sin dejar de ser ellos mismos, perciben que, al ser el medio distinto, algo cambia. Sus respuestas se encuentran más avanzadas que las anteriores. El hecho de estar de manera física o mediática, introduce cambios evidentes en el modo de comunicarse, sin que esto implique obligatoriamente un cambio en la identidad, al menos un cambio radical. En sus respuestas, los estudiantes manifiestan distinta valoración del medio, de sí mismos o de sus interlocutores y esta combinación de factores definirá buena parte de los valores que exhiben en su conducta.

Una estudiante de 21 años del Grado en Biotecnología habla del medio utilizado y dice lo siguiente: "Sí, las conversaciones cara a cara permiten mayor efusividad, además de la utilización del lenguaje no verbal que da más información. También está el hecho de que los sarcasmos, ironías o ciertas bromas; no se captan por igual a través de una pantalla" (1/286). Otra estudiante del Grado en Biotecnología, de 20 años, afirma que las variantes en sus conversaciones tienen que ver más con su interlocutor: "No, aunque a veces depende de con quién hable. Si es alguien a quien suelo ver a diario, no cambia mi forma de expresarme a través de las redes, pero 
con gente a quien no veo tanto, sí puedo hasta hablar más que en persona" (1/285).

Estas respuestas afinan bastante más. Apuntan a un nivel de integración personal mayor y al reconocimiento de la propia complejidad que hay en cada cual.

Estos resultados permiten considerar que es el desarrollo personal el que permite apreciar límites y posibilidades tanto en el cuerpo como en la tecnología, límites que no necesariamente gozan de objetividad, sino que dependen en gran medida de las posibilidades y perspectivas del observador que analiza y que construye. Medio y sujeto solo pueden ser distinguidos por el observador ya que hay entre ellos complementariedad estructural (Maturana, ibid.) $Y$ esta idea de complementariedad de estructuras humanas y de agencias maquínicas (Idhe, ibid.), transforma la visión polarizada y moralizante que muchas veces se ha proyectado sobre el cuerpo y la tecnología.

Algunos estudiantes han accedido a una visión más integrada como resultado del buen uso de su propia libertad y de la confianza en sí mismos y en otros, lo que hace posible la comunicación en profundidad y la intimidad.

Un falso cierre a este problema es hacer del cuerpo el lugar de la autenticidad por su transparencia, cuando no es así. El cuerpo está presente, pero no siempre está abierto y su misma presencia es ambigua. La comunicación cara a cara, también puede estar sometida a un juego de interpretaciones y suplantaciones. Y no es que siempre se pretenda engañar, sino que se utilizan revestimientos formales y se asumen discursos que ocultan más que revelan. Para finalizar esta primera parte de la discusión, sería interesante preguntar si buena parte de las conversaciones que ocurren fuera de la red, en aulas, bares o domicilios particulares, no funcionan de la misma manera.

Y con esta reflexión pasamos a discutir los resultados de analizar las respuestas a la segunda pregunta.

Formamos parte de una cultura global de imágenes y con respecto a la imagen propia, hay todo un despliegue de valores, desde los que se aborda y se vive y que conectan con la experiencia integrada/desintegrada de uno mismo. En el modelo HT los valores meta: Integración/totalidad (etapa 5) y Ser uno mismo (etapa 6), son los valores de referencia, pilares en la construcción y expansión del sí mismo.

Como se indicó en la discusión de las conclusiones de la fase piloto, hay una escisión asociada al proceso de desarrollo. Sin embargo, la búsqueda de protección que ofrece la tecnología en las interacciones virtuales, puede reforzar esta circunstancia y mantener en el tiempo de forma indeseable la experiencia de desintegración. Y es que la imagen es más vulnerable que la propia persona cuando ya no nos pertenece. Este es el principal hallazgo de esta investigación y así lo expresaba una estudiante de Bachillerato, de 17 años: "Sí me lo pienso, soy consciente de que cuando subes una foto puede 
verla todo el mundo y ya no me pertenece a mí, sino a Internet. Antes de subir, tanto imágenes como información personal, lo pienso bien asumiendo lo que conlleva" (2/43).

Hay experiencias con la imagen que remiten a valores de las etapas iniciales, como la necesidad de Autopreservación, valor meta de la etapa 1, que se presenta en los casos en los que los jóvenes evitan colgar imágenes de ellos mismos por miedo a las consecuencias. Los peligros, muchas veces sustentados en casos muy mediatizados, o la necesidad de ejercer un control extremo sobre lo que se sube, responden también al valor Interés personal/control, meta de la etapa 1. Cabe situar en esta etapa inicial la experiencia de sentirse sobrepasado por las infinitas posibilidades que ofrece el medio y que escapan, no solo al control de las consecuencias de una acción casi ingenua sino a la comprensión misma de su sobredimensionamiento. Como ejemplo, la declaración de una estudiante del Grado de Lengua Española y Literatura, de 21 años: "Tengo miedo a mi intimidad" (2/220) que se asocia al valor Asombro/destino, meta también de la etapa primera. Remitimos a los comentarios iniciales de este último apartado sobre la presencia física que están necesariamente vinculados con la intimidad y que trataremos en esta discusión.

Un valor clave del desarrollo en estas edades es la Autoestima, meta de la etapa 3. Muchos jóvenes hacen referencia a los quebraderos de cabeza que les supone decidir qué imagen de sí mismos subir, o refieren la necesidad de que otros amigos/as les apoyen en esa decisión. También aparece manifiesto el interés por la imagen que dan de sí mismos, no sólo en lo relativo a criterios de gusto, sino de ganar prestigio y con ello aceptación y liderazgo, lo que hace referencia al valor Prestigio/imagen, medio de la etapa 3. Así lo declara este joven estudiante del Grado de Lengua Española y Literatura, de 18 años: "Sí, me gusta salir tremendo, guapo y resultón para las chicas. Mis amigos no, porque yo soy el líder, yo soy el jefe" (2/241).

En estas etapas iniciales, la imagen puede ser experimentada como una necesidad de identificación plena con el yo a través de la objetivación visual. Si la imagen no me identifica, se produce una especie de disociación que perjudica el proceso de integración. Pero también se respira, en algunas respuestas de los estudiantes, un dualismo positivo. Con esta naturalidad lo expresa un estudiante de 17 años de segundo de Bachillerato: "(...) muchas veces es por lo que pensarán los demás de mí o de las imágenes, y otras porque no estoy seguro de si me gustan o me identifican" (2/5). Las imágenes hablan de uno mismo, pero 'yo no soy mi imagen'. Los jóvenes presentan algunas interesantes resistencias a ser tratados (juzgados, evaluados, calificados y/o clasificados) desde la imagen proyectada. Estas resistencias son de gran valor por el acoso de los medios de comunicación que sobredimensionan el valor de la imagen, sobre todo femenina, con el objetivo de estimular el consumo de productos y servicios relacionados con la belleza y la salud, valores que se presentan asociados a la juventud y al éxito social. 
La objetivación visual, que ha sido tan útil a la ciencia, lo es también en la comunicación virtual. El modo más frecuente de virtualidad es el cuerpoimagen (Idhe ibid.). Más que nuevas tomas de conciencia relacionadas con las consecuencias de algunas de estas prácticas, presentes en todos los medios de comunicación muy atentos a los riesgos, la cierta cautela a la hora de compartir las imágenes, se deriva de la percepción de indefensión, tal vez por la deslocalización del cuerpo virtual y la imposibilidad consecuente de ser interpretado adecuadamente sin contexto. Estar situado implica estar en el cuerpo, estar localizado (Ihde, ibid.), en algún sentido se es rehén del propio cuerpo al no disponer (su imagen) de la holgura que permite la trascendencia que anuncian los valores de etapas más avanzadas.

El vertiginoso desarrollo tecnológico ha permitido la intercomunicación en tiempo record. Esta sobreaceleración tecnológica ha impedido su necesaria apropiación interna, apropiación que demanda procesos de toma de conciencia necesariamente lentos, que necesitan mucho trabajo personal, alentado desde el respetuoso acompañamiento del compartir.

Algunas respuestas, nos han llevado a debatir sobre un tipo de experiencia liberadora, distinta a las comentadas en otros lugares de este mismo apartado. Aparece claramente referida en la que se transcribe a continuación: "Yo personalmente subo lo que quiero, cuando quiero y como quiero, ya que las redes sociales permiten absoluta libertad. Mis amigas no sé lo que harán" (2/254), de una estudiante de Grado en Lengua Española y Literatura, de 18 años de edad. Se trata de una respuesta significativa y problemática. Las redes sociales alientan una percepción de poder falseada. El uso de redes y otras plataformas de acceso abierto, no es un generoso regalo de las grandes empresas y grupos de comunicación que las mantienen y desarrollan: éstas reciben como contraprestación una rentable información personal, entregada gustosamente por los mismos usuarios (Han 2012; Castells 2009).

Un tema que presenta simultáneamente, interés y confusión, y que resulta necesario abordar por su interés práctico, es el relativo a la intimídad. La Intimidad como valor aparece en el modelo HT en una etapa bastante avanzada del desarrollo (valor medio etapa 6). Los y las jóvenes, aun cuando en sus respuestas hacen numerosas alusiones a la intimidad como un asunto que les preocupa, sus preocupaciones reales están asociadas a valores de las cuatro primeras etapas. Es preciso tomar como referencia la definición que los autores del modelo dan al valor. Intimidad es compartir las fantasías, realidades, pensamientos y sentimientos más profundos mutua, libre y regularmente con otra persona. Esta definición contrasta con el ideario social y juvenil que hay al respecto. Los jóvenes son capaces de captar que la intimidad tiene que ver con el cuerpo y con cierta experiencia de lo secreto. Algunos relacionan la intimidad con la privacidad y con la propiedad de forma confusa. Una estudiante de Bachillerato de 18 años, lo expresa así: "Yo, sinceramente sí me lo planteo, puesto que subes a las redes 
tu vida privada y hay cosas que no te apetece que sepan los demás y no te reprimes por ello, y otras que es mejor que queden en la intimidad" (2/131).

Pero la tecnología también ha permitido que algunos jóvenes estudiantes, se sientan liberados del aburrido e innecesario control sobre los asuntos privados. La respuesta de un estudiante universitario de Grado en Lengua Española y Literatura, de 18 años de edad, da muchas claves:

"Yo no me lo pienso porque creo que la mejor manera de que tus secretos no salgan a la luz es no tenerlos. Afrontar tu vida con sinceridad absoluta hacia el mundo te hace, por un lado, tomar decisiones más reflexionadas, y por otro, no tener la incerteza y la inseguridad de no saber quién sabe la verdad y quién no. Si no tienes nada que ocultar, no hay de qué preocuparse al subir fotos a las redes sociales. Este modo de vida es el que creo que compartimos gran número de jóvenes hoy en día y el que recomiendo" (2/203).

La nueva seguridad tiene algo que ver con una reinterpretada transparencia (Han 2013) que ellos asocian a la sinceridad. Antes no se podía pensar en estar abiertos al mundo pues los límites de la tecnología reducían el espacio de acción y comunicación al ámbito local. Ahora, ¿̇se puede tener intimidad y compartirla con el mundo?

Publicar la intimidad no es asunto de actualidad tecnológica sino práctica común entre poetas y escritores de géneros autobiográficos como las confesiones o los diarios. La intimidad soy yo mismo y solo si se ha trabajado la interioridad, se puede compartir y publicar. De lo contrario, se estarían compartiendo otras cosas: partes de nuestro cuerpo, ideas prestadas, inapropiadas, gestos que desfiguran y hacen difícil el propio reconocimiento. El peligro no está siempre en las redes sino en uno mismo. En muchos casos se comunica un yo falseado, deformado o desfigurado.

Es necesario insistir y profundizar en las diferencias entre identidad/intimidad y privacidad: 'todo soy yo', pero de distinta manera. Lo íntimo hace referencia al 'sí mismo' que difícilmente se refleja en la apariencia pero que desea comunicarse. El valor que lo identifica es Intimidad. La identidad es un conjunto con significado: yo soy muchas cosas, pero expresadas en una totalidad que me identifica. El valor es Integración/totalidad. La privacidad es el sentido de propiedad que tiene o proyectamos sobre nuestra identidad y/o sobre nuestra intimidad, y la cautela puesta en su cuidado.

Esta discusión ha evitado presentar reflexiones que mantengan la dualidad entre cuerpo y tecnología. Hay un punto en el que ambas realidades se encuentran y se integran. En el modelo de valores HT el valor Tecnología como valor medio de la última etapa, permite realizar una visión prolongada de lo humano. Su meta es la Ecoridad, de la misma etapa, que hace referencia al necesario equilibrio entre lo natural, lo humano y lo tecnológico, potenciándose mutuamente.

Cuando el cuerpo es un lugar seguro, puedo expresarlo. Este es el sentido del valor Expresividad/libertad. La conversación cara a cara ocurre en tiempo 
real y no en diferido. El cuerpo es un dato inevitable que se impone, es mensaje y no solo lugar o escenario, se expresa y nos expresa. Cuando nos estamos comunicando con otra persona, los cuerpos, además de regular la comunicación, crean sentido en el intercambio, sentido que no se deja traducir en su conjunto a una elaboración consciente, al igual que ocurre con la obra de arte, su presencia y su expresión se imponen y nos afectan. El cuerpo forma parte del mensaje, tal vez la parte más relevante.

\section{Referencias bibliográficas}

Bard, A. y Sãderqvist, J. (2002). La netocracia: El nuevo poder en la red y la vida después del capitalismo. Madrid: Pearson Educación.

Autor et al. (2015). "Valores asociados a las experiencias del cuerpo en las comunicaciones de los jóvenes" en Prisma Social. № 15.

Autor, M. Mínguez, R. Elexpuru, I. (2016). "Valores, conflicto y desarrollo organizativo: una investigación cualitativa con el Modelo Hall-Tonna". En Educatio Siglo XXI 34 (3), pp. 199-218. http://dx.doi.org/10.6018/j/276021

Castells, M. (2009). Comunicación y poder. Madrid: Alianza, 2009.

Centro de Investigaciones Sociológicas. Barómetro de marzo 2016. Avance de resultados. Estudio $n^{\circ}$ 3131, 2016. Consulta 8 de enero de 2017 (http://datos.cis.es/pdf/Es3131mar_A.pdf)

Centro Reina Sofía sobre Adolescencia y Juventud / FAD."Proyectoscopio. Índices de desarrollo juvenil". Madrid: FAD. 2016 Consulta 8 de enero de 2017 (http://www.proyectoscopio.es/).

Fundación Telefónica. (2016). La Sociedad de la Información en España 2015. Madrid: Fundación Telefónica- Ariel.

Hall, B.P. (1986). The Genesis Effect: Personal and Organizational Transformations. New York: Paulist Press.

Hall, B.P. (1995) Values Shift: Personal and Organizational Development. New York: Twin Lights Publishing.

Hall, Brian P. (2000). "El desarrollo de valores y las organizaciones que aprenden". Pp. 27-53 en Liderazgo y Organizaciones que aprenden, coordinado por A. Villa. Bilbao: ICE- Universidad de Deusto.

Hall, B.P. (1989). Harari, O. Ledig, B. and Tondow, M. Manual for the Hall-Tonna Inventory of Values. New York: PaulistPress, 1986. (Versión castellana ICE de la Universidad de Deusto. 
Han, B-Ch. (2012). La sociedad del cansancio. Barcelona: Herder.

Han, BCh. (2013). La sociedad de la transparencia. Barcelona: Herder.

Han, B-Ch. (2015). El aroma del tiempo. Un ensayo filosófico sobre el arte de demorarse. Barcelona: Herder.

Ihde, D. (2004). Los cuerpos en la tecnología. Nuevas tecnologías: nuevas ideas acerca de nuestro cuerpo. Barcelona: UOC.

Instituto Nacional de Estadística (14 de diciembre, 2016). "Ciencia, tecnología y sociedad de la información. Población que usa Internet (en los últimos tres meses)". Madrid: INE. Consulta 8 de enero de 2017. (http://www.ine.es/ss/Satellite?L=es_ES\&C=INESeccion_C\&cid=1259925528782 $\& p=12547351$ 10672\&pagename=ProductosYServicios\%2FPYSLayout\&param3= 1259924822888).

Korres, O. and Elexpuru, I. (2015a). "Values Perceived by Teens in Their Preferred Television Series Character Through the Hall-Tonna Document Analysis". International Dialogues on Education: Past and Present 2 (2): 144160. Consulta 8 de enero de 2017 (http://www.ide-journal.org/article/2015volume-2-number-2-values-perceived-by-teens-in-their-preferred-televisionseries-character-through-the-hall-tonna-document-analysis/).

Korres O. y Elexpuru, I. (2015b). "La medición e identificación de valores. Complementariedad entre los modelos de Schwartz y Hall-Tonna". Revista Internacional de Educación y Aprendizaje 3(1): 89-101. Consulta 8 de enero de 2017

(http://journals.epistemopolis.org/index.php/educacion/article/view/590)

Lasén, A. y Casado, E. comps. (2014). Mediaciones Tecnológicas: cuerpos, afectos y subjetividades. Madrid: CIS/Universidad Complutense de Madrid, 2014.

Maturana, H. (1996). El sentido de lo humano. Dolmen: Santiago de Chile, 1996.

Puente, H. Fernández Ruíz, M. Costán, Br. y López Jiménez, M. "Los estudios sobre jóvenes y TICs en España". Revista de Estudios de Juventud 110: 155172, 2015. Consulta 8 de enero de 2017. (http://www.injuve.es/sites/default/files/2016/44/publicaciones/8._los_estudio s_sobre_jovenes_y_tics_en_espana.pdf)

Pardo, J.L. (2011). El CsO. Valencia: Pretextos.

Valuestech. Hall-Tonna Documents. Ohio CA: Valuestech, 2002. (Versión castellana Universidad de Deusto, 2007).

Žižek, S. (2006). Órganos sin Cuerpo. Pretextos: Valencia 